\title{
Thermo-structural analyses of the in-vessel components of the ITER collective
} Thomson scattering system

Vidal, C.; Luís, R.; Pereira, B.; Ferreira, R.; Gonçalves, B.; Korsholm, Søren Bang; Lopes, A.; Klinkby, Esben Bryndt; Nonbøl, Erik; Jessen, M.

Total number of authors:

14

Published in:

Fusion Engineering and Design

Link to article, DOI:

10.1016/j.fusengdes.2019.02.048

Publication date:

2019

Document Version

Peer reviewed version

Link back to DTU Orbit

Citation (APA):

Vidal, C., Luís, R., Pereira, B., Ferreira, R., Gonçalves, B., Korsholm, S. B., Lopes, A., Klinkby, E. B., Nonbøl, E., Jessen, M., Salewski, M., Rasmussen, J., Lauritzen, B., \& Larsen, A. W. (2019). Thermo-structural analyses of the in-vessel components of the ITER collective Thomson scattering system. Fusion Engineering and Design, 140, 123-132. https://doi.org/10.1016/j.fusengdes.2019.02.048

\section{General rights}

Copyright and moral rights for the publications made accessible in the public portal are retained by the authors and/or other copyright owners and it is a condition of accessing publications that users recognise and abide by the legal requirements associated with these rights.

- Users may download and print one copy of any publication from the public portal for the purpose of private study or research.

- You may not further distribute the material or use it for any profit-making activity or commercial gain

- You may freely distribute the URL identifying the publication in the public portal 


\title{
Thermo-structural analyses of the in-vessel components of the ITER Collective Thomson Scattering System
}

\author{
C. Vidal ${ }^{1, *}$, R. Luís ${ }^{1}$, B. Pereira ${ }^{1}$, R. Ferreira ${ }^{1}$, B. Gonçalves ${ }^{1}$, S. B. Korsholm ${ }^{2}$, A. Lopes ${ }^{1}$, E. \\ Klinkby $^{3}$, E. Nonbøl' ${ }^{3}$, M. Jessen ${ }^{2}$, M. Salewski ${ }^{2}$, J. Rasmussen², B. Lauritzen ${ }^{3}$, A.W. Larsen ${ }^{2}$ \\ ${ }^{1}$ Instituto de Plasmas e Fusão Nuclear, Instituto Superior Técnico, Universidade de Lisboa, \\ Av. Rovisco Pais 1, 1049-001 Lisboa, Portugal \\ ${ }^{2}$ DTU Physics, Technical University of Denmark, Fysikvej, 2800 Kgs, Lyngby, Denmark \\ ${ }^{3}$ DTU Nutech, Technical University of Denmark, DTU Ris $\phi$ Campus, Frederiksborgvej 399, \\ DK-4000 Roskilde, Denmark \\ *Corresponding author: cvidal@ipfn.tecnico.ulisboa.pt
}

\begin{abstract}
The Collective Thomson Scattering (CTS) diagnostic system will be used at ITER to provide spatial and temporal measurements of fast ion velocity distributions. The diagnostic is based on the CTS principle, where a microwave beam scatters off electrons in the plasma. The scattered radiation is then collected and measured, providing information about the fast ions. The system components are either considered in-vessel or ex-vessel depending on their location in the port plug. In this work, preliminary thermo-structural analyses were performed on four in-vessel components using the finite-element method and the commercial software ANSYS Mechanical v18.0. The analyses indicate that active cooling will be required for most of the analysed components. The thermal stresses will be used to perform the structural assessment of these components based on the RCC-MR code.
\end{abstract}

Keywords: ITER; Collective Thomson Scattering system; thermo-structural analyses; active cooling. 


\section{Nomenclature}

$\begin{array}{ll}\rho & \text { resistivity } \\ \mu_{0} & \text { permeability of free space }\left(1.25664 \times 10^{-6} \mathrm{NA}^{-2}\right) \\ A t & \text { tensile stress area } \\ \text { CAD } & \text { computer-aided design } \\ \text { CTS } & \text { Collective Thomson Scattering } \\ \text { DFW } & \text { diagnostic first wall } \\ D_{h} & \text { hydraulic diameter } \\ f & \text { frequency } \\ \text { FE } & \text { finite element } \\ \text { FEM } & \text { finite element method } \\ \text { Fi } & \text { initial pre-load } \\ \text { IG } & \text { ITER grade } \\ \text { ITER } & \text { International Thermonuclear Experimental Reactor } \\ k & \text { thermal conductivity } \\ N u & \text { Nusselt number } \\ P r & \text { Prandtl number } \\ R e & \text { Reynolds number } \\ z 0 & \text { impedance of free space }(376.73 \Omega) \\ 3 D & \text { 3-dimensional }\end{array}$

\section{Introduction}

ITER, currently one of the most relevant energy-related projects worldwide [1], is being built in southern France (Cadarache). More than 30 countries are collaborating in the design of the first nuclear fusion reactor to produce net energy (in which the total power produced during a fusion plasma pulse is more than the power injected to heat the plasma) [1]. ITER is planned to produce 500MW of fusion power, more than 30 times higher than the world record held by the Joint European Torus (JET). Due to its unprecedented fusion power output, high availability and reliability diagnostics systems are required to guarantee a safe operation of ITER.

To assess the fusion performance and ensure safe operations at ITER, knowledge of the spatial and energy distribution of fusion-born alpha-particles in the plasma is required. For this purpose, a Collective Thomson Scattering (CTS) diagnostic is being designed. The diagnostic is based on characterizing light scattered by the interaction between a powerful injected source beam and ion-driven fluctuations in the electron density of the plasma. The primary role of the diagnostic is to deliver spatially resolved information on the alpha-particle density and velocity distributions, with supplementary roles regarding measurements of the ion temperature, plasma rotation, and possibly the fuel-ion ratio. Integrated data analysis of CTS and gamma-ray spectrometers allows the determination of $2 \mathrm{D}$ velocity distribution functions of the alphas and 
consequently the determination of alpha-particle energy spectra and densities [2]. The system makes use of a powerful $1 \mathrm{MW} 60 \mathrm{GHz}$ gyrotron source, which, through a system of waveguides and mirrors, delivers the probing radiation through the closure plate of the equatorial port plug into the plasma via a cut-out in the diagnostic first wall. The response signal is collected on separate mirrors through a receiver cut-out in the diagnostic first wall and transmitted via waveguides through the port cell and back to the diagnostic building [3-7]. Due to the large openings in the plasma facing first wall, the in-vessel components in the CTS port plug will be subjected to high radiation doses from the plasma neutrons and from the gamma-ray photons generated in nuclear interactions in the surrounding materials. This is suggested by an earlier study of a plasma-facing CTS mirror placed on the high-field side which was later abandoned [8]. Similarly, these radiation doses will contribute to the thermal loads in the low-field-side CTS system and may cause irradiation-induced changes in the material properties, which can compromise the integrity of the components during the lifetime of ITER.

This paper presents the outcome of preliminary thermo-structural analyses on four in-vessel components: pre-launcher, launcher and receiver mirrors and launcher mitre bends. The pre-launcher and launcher mirrors are subjected to high thermal loads since they are directly facing the plasma. The temperature distribution on the components was analysed and the critical areas/points identified in order to evaluate the need of implementing an active cooling setup.

\section{Finite Element Model}

\subsection{Model Description}

The CAD model of the CTS system used for the FE analyses can be seen Figure 1 of reference [9]. In this CTS model, the positions and shapes of the pre-launcher, launcher and primary receiver mirrors surfaces are defined. From these surfaces, 3D solid models were developed and are shown in Figure 1. 


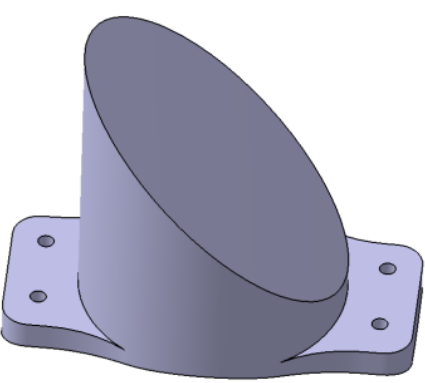

(a)

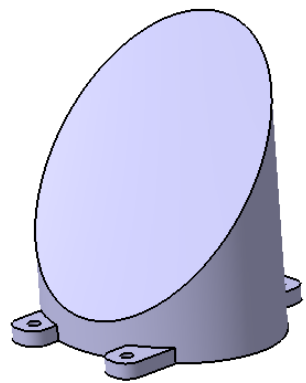

(b)

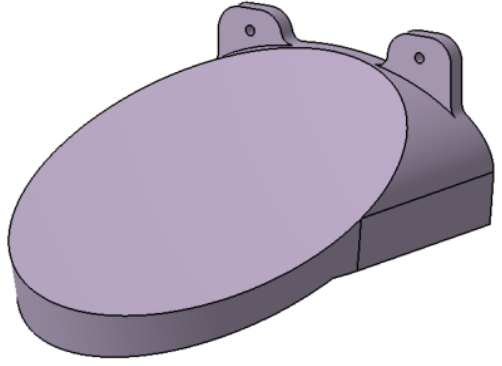

(c)

Figure 1 - Geometry of the: (a) pre-launcher mirror M0, (b) launcher mirror M1 and (c) primary receiver mirror M2.

The surroundings of the mirrors were taken into account since radiation exchange between the different components is expected to play an important role on the resulting temperatures. These surrounding components were considered in the analyses by using representative surfaces matching the faces of the drawer, the diagnostic first wall (DFW) and the openings facing the plasma.

The launcher mitre bends were analysed along with their adjacent components since these have impact on the results. The CAD model with all the components that are part of the analyses can be seen in Figure 2. The nearest drawer surfaces were used to create the enclosure.

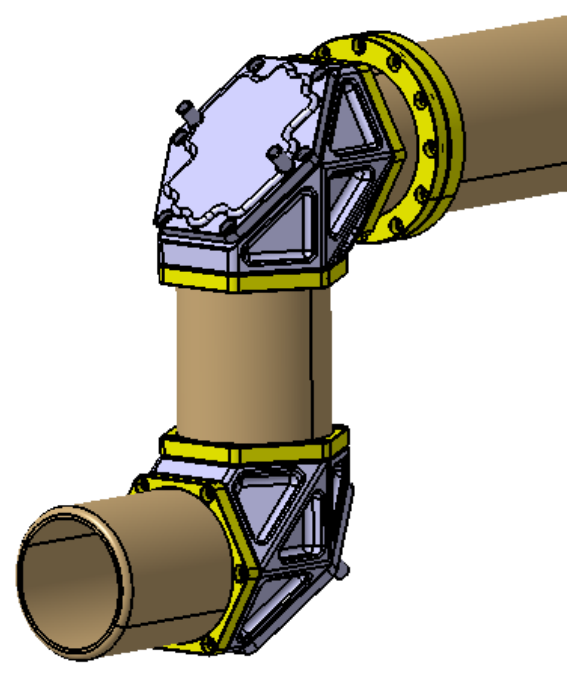

(a)

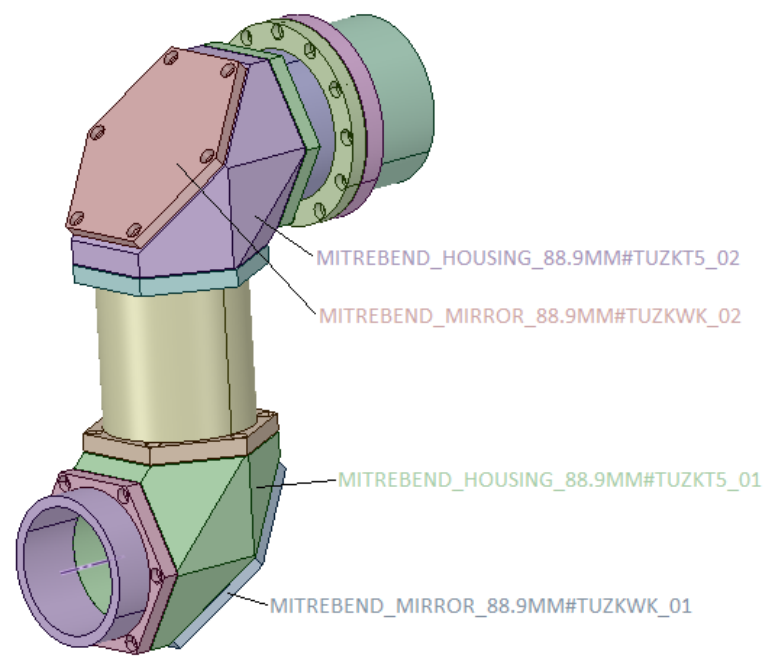

(b)

Figure 2 - (a) CAD model for the analyses of the launcher mitre bends; (b) Launcher mitre bends baseline model with the identification of the components of interest. 


\subsection{Element Types}

The software ANSYS Workbench v18.2 was used for both analyses, thermal and structural. The elements used for each analysis are described in Table 1.

\begin{tabular}{|l|l|l|}
\hline Analysis & Element type & Description \\
\hline \multirow{5}{*}{ Thermal } & SOLID87 & 3-D 10-Node thermal solid \\
\cline { 2 - 3 } & SOLID90 & 3-D 20-Node thermal solid \\
\cline { 2 - 3 } & SHELL131 & 4-Node thermal shell \\
\cline { 2 - 3 } & SHELL132 & 8-Node thermal shell \\
\cline { 2 - 3 } & SURF152 & 3-D thermal surface effects \\
\cline { 2 - 3 } & SURF252 & 3-D radiosity surface \\
\cline { 2 - 3 } & FLUID116 & coupled thermal-fluid pipe \\
\cline { 2 - 3 } & CONTA174 & contact element \\
\cline { 2 - 3 } & TARGE170 & contact element \\
\hline \multirow{5}{*}{ Structural } & SOLID186 & 3-D 20-Node homogeneous structural solid \\
\cline { 2 - 3 } & SOLID187 & 3-D 10-Node homogeneous structural solid \\
\cline { 2 - 3 } & CONTA174 & contact element \\
\cline { 2 - 3 } & TARGE170 & contact element \\
\hline
\end{tabular}

Table 1 -Elements used in the analyses.

Elements SOLID87 and SOLID90 were used to mesh all components for the thermal analyses. The enclosure was modelled with SHELL131 elements, which are 3D layered shell elements that have in-plane and through-thickness thermal conduction capability. Contact connections were modelled using CONTA174 and TARGE170. CONTA174 is used to represent contact and sliding between 3D target surfaces and a deformable surface defined by this element. The target surface is defined by the 3D target element type, TARGE170. The element CONTA174 is located on the surfaces of $3 \mathrm{D}$ solid or shell elements with midsize nodes. It has the same geometric characteristics as the solid/shell element face with which it is connected. Contact occurs when the element surface penetrates an associated target surface. SURF152 and SURF252 were used to consider heat flow and radiation surface effects. They are applicable to 3D thermal analyses and they may be overlaid onto an area face of any 3D solid or shell thermal element that supports temperature degrees of freedom. FLUID116 was the element used to mesh the water inside the cooling channels. It is a 3D element with the ability to conduct heat and transmit fluid between its two primary nodes. Convection may be accounted for additional nodes, convection areas or for surface elements, such as SURF152. Elements SOLID187 and SOLID186 were used to mesh all components for the static structural analyses. The element BEAM188 was used on some bolted connections. This is a 3D element with 6 or 7 degrees of freedom at each node (translations in the $\mathrm{x}, \mathrm{y}$, and $\mathrm{z}$ directions and rotations about the $\mathrm{x}, \mathrm{y}$, and $\mathrm{z}$ directions). The element is based on the Timoshenko beam theory [10]. 


\subsection{Material Properties}

The baseline material used for all components was the stainless steel 316L(N)-IG, since this is a common material used in ITER components. The properties of this material were extracted from reference [11] and are temperature dependent. The maximum operating temperature allowed for this stainless-steel under neutron irradiation is $450^{\circ} \mathrm{C}$ [11].

The CuCrZr-IG alloy was also used since more promising results were obtained with this material as will be shown in section 3. The material properties were also extracted from reference [11]. The maximum operating temperature for this alloy is $350^{\circ} \mathrm{C}$ [11].

\subsection{Loads and Boundary Conditions}

Thermo-structural analyses were performed to assess the structural integrity of the CTS components due to thermal loads. The thermal analyses consisted on transient models where two pulses of 400 seconds and a dwell time of 1400 seconds were considered [12]. For each component, thermal analyses were carried out to obtain the temperature distribution, which was then imported, as an external load, into the static structural analyses to determine the thermal stresses and total displacements on the component. The thermal and structural problems can be decoupled in this way since the deformation is negligible for the heat loads.

For the mirrors in the high-power transmission line, the effect of 1MW gyrotron beam at $60 \mathrm{GHz}$ was taken into account in the thermal analyses. The power distribution across the components was determined by equation 1 :

$P(x, y)=\frac{P_{t o t}}{\pi} \frac{2}{w_{x} w_{y}} \exp ^{-2\left(\frac{x^{2}}{w_{x}^{2}}+\frac{y^{2}}{w_{y}^{2}}\right)}$

where $P_{\text {tot }}$ is the total beam power, $x$ is the distance from the mirror centre in the x direction, $y$ is the distance from the mirror centre in the $\mathrm{y}$ direction, $w_{x}$ is the Gaussian beam width in the $\mathrm{x}$ direction and $w_{y}$ is the corresponding width in the y direction.

As the power is not totally absorbed by the components, equation 2 was used to compute the absorbed percentage assuming perfect surfaces [13]:

$A=\left(\frac{4}{z_{0}}\right) \sqrt{\pi f \mu_{0} \rho}$

For steel components, a copper coating was considered which directly influenced the absorbed percentage of power. Considering a conservative temperature of $600^{\circ} \mathrm{C}$ and a $20 \%$ increase in 
temperature due to irradiation, the electrical resistivity of copper was set to $6.912 \mu \Omega$.cm [14]. The absorbed percentage was computed as:

$A=\left(\frac{4}{376.73 \Omega}\right) \sqrt{\pi \times 60 G H z \times 1.2566 \times 10^{-6} \frac{\Omega . s}{m} \times 6.912 \mu \Omega . c m}=0.136 \%$

The beam has a duty cycle of 50\% [15]. The application of the absorbed power was done as a heat flow input in the FE model.

\subsubsection{Pre-launcher Mirror M0 and Launcher Mirror M1}

Since the pre-launcher and launcher mirrors share the same enclosure, a common thermal analysis was carried out to take into account the radiation exchange between these two components. The thermal model included the bodies of the components, the beam elements representing the fluid flow and the surfaces representing the drawer, first wall and plasma.

The loads and boundary conditions for the thermal analysis were the following:

- $\quad$ Plasma heat flux of $500 \mathrm{~kW} / \mathrm{m}^{2}[16]$;

- $\quad$ Stray radiation of $25 \mathrm{~kW} / \mathrm{m}^{2}[16]$;

- Absorbed percentage of the microwave beam applied to each mirror surface as explained in section 2.4;

- Internal heat generation of $2 \mathrm{~W} / \mathrm{cm}^{3}$ due to nuclear loads in $\mathrm{M} 1 \mathrm{mirror}$ [9];

- Internal heat generation of $1 \mathrm{~W} / \mathrm{cm}^{3}$ due to nuclear loads in $\mathrm{M} 0$ mirror [9];

- Imposed temperature of $150^{\circ} \mathrm{C}$ on the external surfaces representing the drawer walls [13];

- Imposed temperature of $150^{\circ} \mathrm{C}$ on the mirrors bases [13];

- $\quad$ Imposed temperature of $300^{\circ} \mathrm{C}$ in the enclosure surface representing the first wall [13];

- Radiation exchange between surfaces through the definition of a common enclosure: emissivity value of 0.1 for polished surfaces and 0.5 for the remaining surfaces.

Regarding the nuclear loads, since the values presented in [9] are similar for both materials, the same value of internal heat generation was used. The plasma heat flux of $500 \mathrm{~kW} / \mathrm{m}^{2}$ in addition to the volumetric internal heat generation is set according to the required load 
specifications [13]. In steady-state conditions the plasma heat flux will be substantially lower in ITER, so that our computed temperatures and thermal stresses have a safety margin [8].

Instead of using heat fluxes, the plasma and stray radiation was input into the model as an equivalent black body temperature according to equation 3 :

$$
q=\varepsilon \sigma\left(T_{e q}^{4}\right) \Leftrightarrow 525 \frac{K W}{m^{2}}=1 \times 5,6697 \times 10^{-8} W^{-2} K^{-4} \times\left(T_{e q}^{4}\right) \Leftrightarrow T_{e q}=\mathbf{1 4 7 1}^{\circ} \boldsymbol{C}
$$

By doing this, the computing time is significantly reduced and the results are not significantly affected.

For the structural analyses, each component was individually analysed. The temperature distribution obtained from the thermal analyses was used as the only input load. Regarding the boundary conditions, the mirror was considered to be bolted to the drawer. A support body for each mirror was therefore designed and standard steel was used as the material. All the degrees of freedom were set to zero in the boundary of the support bodies. Frictional contact with a friction coefficient of 0.2 was defined between the mirrors and the respective support body. The attachment of the two bodies was modelled through bolted connections where pre-stress could be added. For the pre-launcher mirror M0, M6 bolts were considered, while M8 bolts were used in the launcher mirror. The constraint equations for the bolted connections were applied to areas with the section of a washer compatible with the chosen bolt size.

When pre-stress was used in the model, the analysis was split into three load steps. The pre-stress was applied in the first load step and kept "on" through the whole analysis. The temperature load was only activated in the last load step. Therefore, the temperature load was applied to an already deformed and stressed body, leading to a more realistic simulation.

In order to compute the initial preload to be applied on the bolted connections, the initial tensile stress $\sigma_{\mathrm{t}}$ was calculated using equation 4 :

$$
\sigma_{t}=\alpha \times \sigma_{y}
$$

Using a factor $\alpha$ of 0.6 and considering a yield strength $\sigma_{y}$ of $640 \mathrm{MPa}$ (grade 8.8 bolt), the initial stress obtained was $384 \mathrm{MPa}$. The initial preload $\mathrm{F}_{\mathrm{i}}$ was calculated as described in equation 5:

$$
F_{i}=A_{t} \times \sigma_{t}
$$

For a M8 bolt the tensile stress area $A_{t}$ is $36.61 \mathrm{~mm}^{2}$ and for a M6 bolt it is $20.12 \mathrm{~mm}^{2}$. Thus, the initial preload value $\mathrm{F}_{\mathrm{i}}$ was $\sim 14 \mathrm{kN}$ for the M8 bolts and $\sim 7 \mathrm{kN}$ for the M6 bolts. 


\subsubsection{Primary Receiver Mirror M2}

For the receiver mirror, the thermal analysis setup was similar to the previous case, with the difference that the receiver mirror was not subjected to the microwave beam power. Thus, the loads and boundary conditions were:

- A temperature of $1471^{\circ} \mathrm{C}$ equivalent to the plasma and stray radiations applied to the plasma representing surface;

- Internal heat generation of $4 \mathrm{~W} / \mathrm{cm}^{3}$ due to nuclear loads [9];

- $\quad 150^{\circ} \mathrm{C}$ on the external surfaces representing the drawer walls;

- $\quad 150^{\circ} \mathrm{C}$ on the mirrors bases;

- $300^{\circ} \mathrm{C}$ in the enclosure surface representing the first wall;

- Radiation exchange between surfaces through the definition of a common enclosure: emissivity value of 0.1 for polished surfaces and 0.5 for the remaining surfaces.

Regarding the nuclear loads, for the same reason stated on the previous sub-section, the same value of internal heat generation was used for the two tested materials. Also, as in section 2.4.1, the plasma radiation was computed with a safety margin with respect to steady-state conditions.

For the structural analysis, the setup was similar to that described in section 2.4.1. The temperature distribution from the thermal analysis was imported as a load. A standard steel support body was designed, and all the degrees of freedom were set to zero in its boundary. Frictional contact with a friction coefficient of 0.2 was defined between the mirror and the support body. The attachment of the two bodies was modelled through two bolted connections where pre-stress could be added. A bolt diameter of $8 \mathrm{~mm}$ was used. The procedure for inputting the temperature distribution and the pre-stress through the use of 3 load steps remained the same as in the previous case (see section 2.4.1).

\subsubsection{Launcher Mitre Bends}

The mirrors of the launcher mitre bends also absorb part of the microwave beam power, and, consequently, this load was considered in the analyses (see section 2.4). Internal heat generation derived from nuclear loads was also added, as listed in Table 2 (see Figure 3 for component identification). All values were taken from [9] and [17]. 


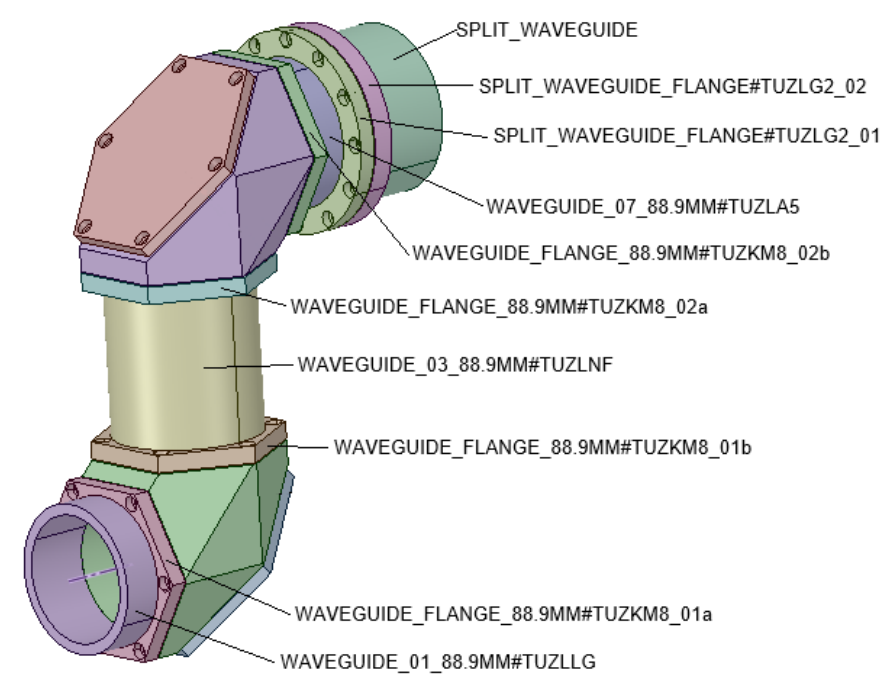

Figure 3 - List of components adjacent to the mitre bends.

\begin{tabular}{|l|c|}
\hline \multicolumn{1}{|c|}{ Component } & $\begin{array}{c}\text { Internal } \\
\text { Heat } \\
\text { Generation, } \\
\text { W/cm }\end{array}$ \\
\hline WAVEGUIDE_01_88.9MM\#TUZLLG & 0.341 \\
\hline WAVEGUIDE_03_88.9MM\#TUZLNF & 0.129 \\
\hline WAVEGUIDE_07_88.9MM\#TUZLA5 & 0.056 \\
\hline WAVEGUIDE_FLANGE_88.9MM\#TUZKM8_01a & 0.226 \\
\hline WAVEGUIDE_FLANGE_88.9MM\#TUZKM8_01b & 0.131 \\
\hline WAVEGUIDE_FLANGE_88.9MM\#TUZKM8_02a & 0.132 \\
\hline WAVEGUIDE_FLANGE_88.9MM\#TUZKM8_02b & 0.061 \\
\hline SPLIT_WAVEGUIDE_FLANGE\#TUZLG2_01 & 0.048 \\
\hline SPLIT_WAVEGUIDE_FLANGE\#TUZLG2_02 & 0.041 \\
\hline SPLIT_WAVEGUIDE & 0.041 \\
\hline MITREBEND_HOUSING_88.9MM\#TUZKT5_01 & 0.155 \\
\hline MITREBEND_HOUSING_88.9MM\#TUZKT5_02 & 0.102 \\
\hline MITREBEND_MIRROR_88.9MM\#TUZKWK_01 & 0.155 \\
\hline MITREBEND_MIRROR_88.9MM\#TUZKWK_02 & 0.102 \\
\hline EPP12_DSM03_CLMN01_SHIELD_BACK_FILLING_DIAG\#VHXUZV & 0.341 \\
\hline Boron Carbide Block & 0.5 \\
\hline
\end{tabular}

Table 2 - Nuclear loads applied to the components in the thermal analysis of the launcher

mitre bends.

As the launcher mitre bends will not be directly exposed to the plasma, a plasma representing surface was not modelled. Temperature boundary conditions were applied to the surfaces representing the drawer. The temperature imposed on all surfaces was $150^{\circ} \mathrm{C}$, because the launcher mitre bends are only enclosed by drawer walls and not by the DFW. 
Radiation exchange between the enclosure and the external surfaces of the components was considered with an emissivity value of 0.5 .

As previously described in sections 2.4.1 and 2.4.2, for the structural analyses, the temperature distribution obtained from the thermal analyses was used as an input load.

\subsection{Baseline Model and Cooling Setups}

In some cases, after running the thermal analysis it was observed that the estimated operation temperatures were well above the maximum allowed temperature of operation defined by the ITER Organization for stainless steel 316L (N)-IG under neutron irradiation. As the mirrors are plasma-facing components, changes in the design would not suffice to comply with the temperature requirements. Therefore, active cooling should be implemented. As specified in [13], the inlet temperature for the cooling channels is $70^{\circ} \mathrm{C}$ and the maximum allowable temperature for the outlet is $126^{\circ} \mathrm{C}$. The analysis of active cooling was done using fluid pipe elements. In order to model this process, it was necessary to input an inlet temperature $\left(70^{\circ} \mathrm{C}\right)$ and a mass flow rate $(1 \mathrm{~kg} / \mathrm{s})$ to this fluid pipe element.

A convection coefficient was defined to model the heat exchange between these fluid pipe elements and the analysed component. Equation 6 provides a correlation for the internal flow, subjected to the following conditions: i) turbulent and fully developed flow; ii) Prandtl number value between 0,6 and 160; iii) $R e$ above 10000 and iv) fluid temperature below surface temperature.

$$
N u=0,023 \times \operatorname{Re}^{4 / 5} \times \operatorname{Pr}^{0,4}
$$

where $N u$ is the Nusselt number, $R e$ is the Reynolds number and $P r$ is the Prandtl number.

The convection coefficient $\mathrm{h}$ was then computed using equation 7

$$
h=\frac{N u \times k}{D_{h}}
$$

where $k$ is the thermal conductivity of the material and $D_{h}$ is the hydraulic diameter.

\subsubsection{Pre-launcher Mirror M0, Launcher Mirror M1 and Receiver Mirror M2}

For the pre-launcher mirror, launcher mirror and receiver mirror, channels with lengths of 376mm (Figure 4), 822mm (Figure 5) and 2550mm (Figure 6) were designed. The channel centrelines were modelled at $14.5 \mathrm{~mm}, 18 \mathrm{~mm}$ and $12 \mathrm{~mm}$ from the mirror surface, respectively in the pre-launcher mirror, launcher mirror and receiver mirror, leading to a minimum thickness 
between the flowing water and the outside of $6.5 \mathrm{~mm}, 10 \mathrm{~mm}$ and $4 \mathrm{~mm}$. For all mirrors, the straight portions of the channel centreline were spaced by $25 \mathrm{~mm}$, leading to a local thickness between portions of $9 \mathrm{~mm}$.

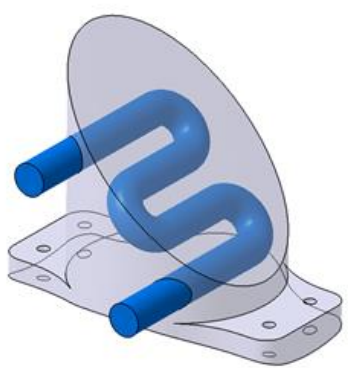

a)

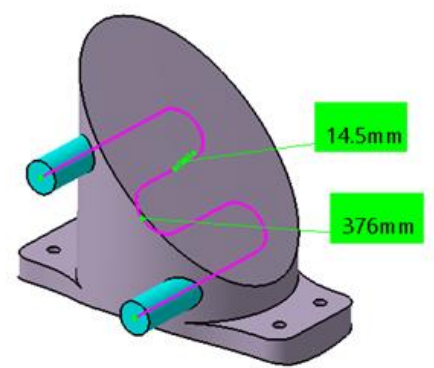

b)

Figure 4 - a) Pre-Launcher water channel; b) Pre-Launcher water channel data.

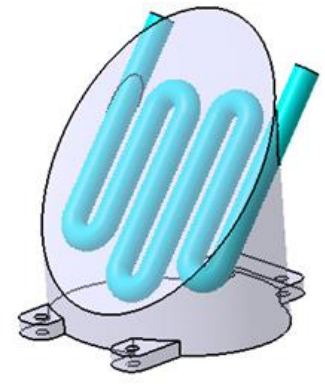

a)

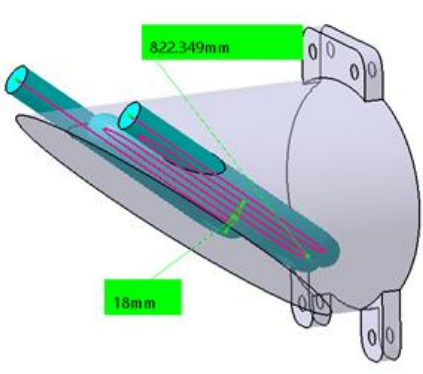

b)

Figure 5 - a) Launcher water channel; b) Launcher water channel data.

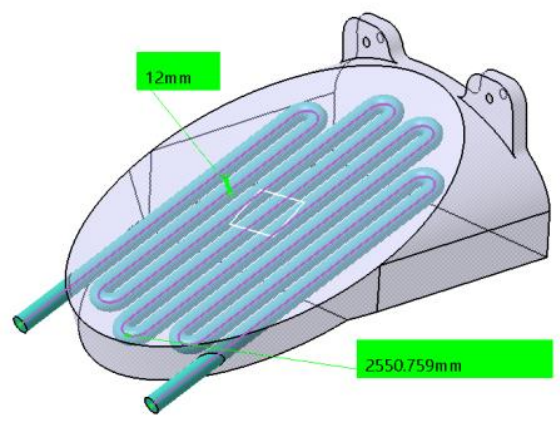

Figure 6 - Receiver mirror cooling setup.

\subsubsection{Launcher Mitre Bends}

Regarding the launcher mitre bends, passive cooling was first considered by increasing the mirrors thickness and changing the material. This proved to be insufficient and active cooling was then considered. 
The convection coefficients were calculated according to sub-section 2.5 , considering an average temperature of $70.5^{\circ} \mathrm{C}$, as the water enters the system at $70^{\circ} \mathrm{C}$ and exits at a maximum temperature of $71^{\circ} \mathrm{C}$.

\section{Results and Discussion}

\subsection{Mesh Quality Assessment}

Before running the whole set of analyses, a suitable mesh size and quality was identified. This was performed using the model of the launcher mirrors that is described in sub-section 2.4.1 and controlling the element size of the mirror bodies. A Hex Dominant method for meshing was considered for this purpose. Using the stainless steel 316L (N)-IG actively cooled models for both mirrors, transient analyses with periods of 400 seconds and static structural analyses using the obtained temperature distribution as an input were carried out for several element sizes.

As shown in Table 3, the temperature and displacement results were found to be approximately constant for the considered range of element sizes. Although higher values of element size could be used, a general element size of $3 \mathrm{~mm}$ was used throughout the analyses. This choice was based on the fact that the deformed shapes of the mirrors had to be exported after the analyses for prototype testing and with a smaller element size smoother shapes could be obtained.

\begin{tabular}{|c|c|c|c|c|c|}
\hline Element Size $[\mathbf{m m}]$ & $\mathbf{7}$ & $\mathbf{6}$ & $\mathbf{5}$ & $\mathbf{4}$ & $\mathbf{3}$ \\
\hline Number of Elements & 22877 & 26945 & 38898 & 59763 & 122401 \\
\hline Temperature in mirror M0 $\left[{ }^{\circ} \mathbf{C}\right]$ & 268.3 & 273.7 & 269.9 & 269.4 & 269.2 \\
\hline Water Temperature in mirror $\mathbf{M 0}\left[{ }^{\circ} \mathbf{C}\right]$ & 70.3 & 70.3 & 70.3 & 70.3 & 70.3 \\
\hline Temperature in mirror M1 $\left[{ }^{\circ} \mathbf{C}\right]$ & 207.2 & 207.2 & 207.3 & 207.3 & 207.3 \\
\hline Water Temperature in mirror M1 $\left[{ }^{\circ} \mathbf{C}\right]$ & 70.7 & 70.7 & 70.7 & 70.7 & 70.7 \\
\hline Displacement in mirror M0 $[\mathbf{m m}]$ & 0.247 & 0.247 & 0.247 & 0.247 & 0.247 \\
\hline Displacement in mirror $\mathbf{M 1 ~}[\mathbf{m m}]$ & 0.437 & 0.437 & 0.437 & 0.437 & 0.437 \\
\hline
\end{tabular}

Table 3 - Mesh convergence results.

\subsection{Pre-launcher Mirror M0 and Launcher Mirror M1}

The transient thermal analyses conducted on both stainless steel 316L (N)-IG launcher mirrors, M0 and M1, without cooling channels showed that after a pulse of 400 seconds, the peak temperature value on both mirrors was above the allowable limit of $450^{\circ} \mathrm{C}$, as presented in Figure 7. 


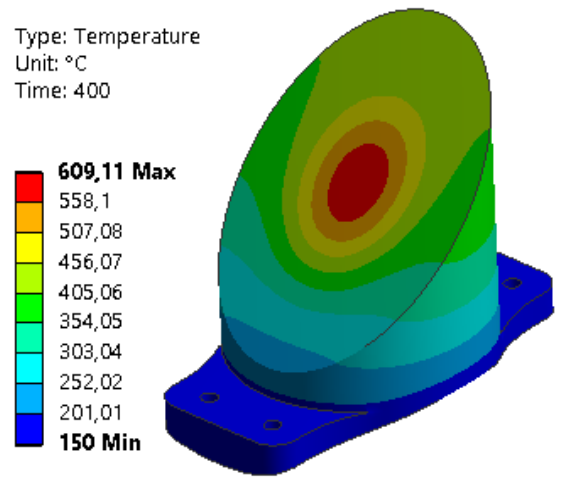

a)

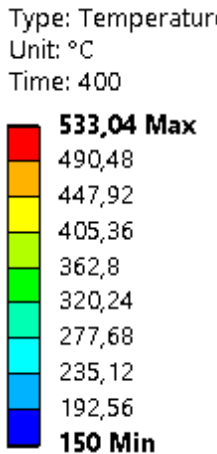

150 Min

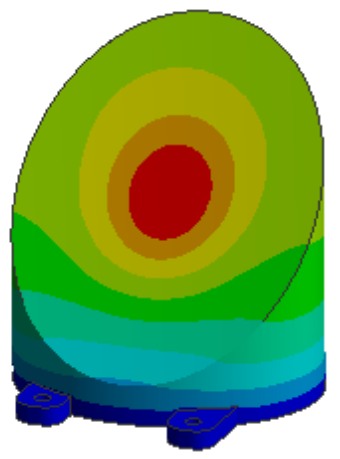

b)

Figure 7 - Temperature distribution on stainless steel a) pre-launcher mirror M0 and b) launcher mirror M1.

Therefore, models of both mirrors with cooling channels were then analysed. Figure 8 shows that the peak temperature values of the actively cooled models after a pulse of 400 seconds were lower than the operating limit temperature.
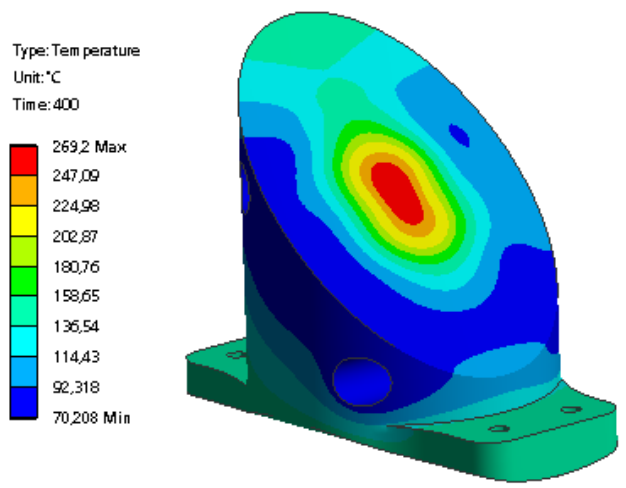

a)

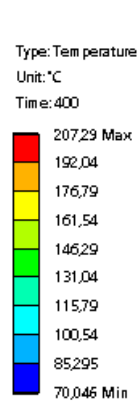

b)

Figure 8 - Temperature distribution on cooled stainless steel a) pre-launcher mirror M0 and

b) launcher mirror M1.

After computing the temperature distribution on both launcher mirrors, static structural analyses were performed. Since the yield strength depends on the temperature, the allowable value for maximum stress varies for each mirror. For a temperature of $207.3^{\circ} \mathrm{C}$ the yield strength is about $142 \mathrm{MPa}$ and for a temperature of $269.2^{\circ} \mathrm{C}$ the value is about $131 \mathrm{MPa}$. It can be seen in Figure 9 that the stresses on both mirrors are higher than the respective yield strength value. 


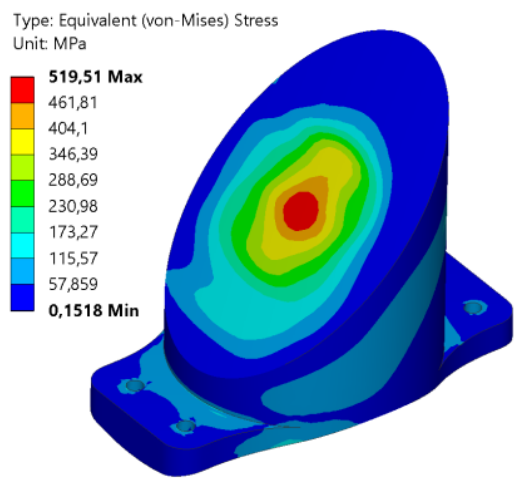

a)

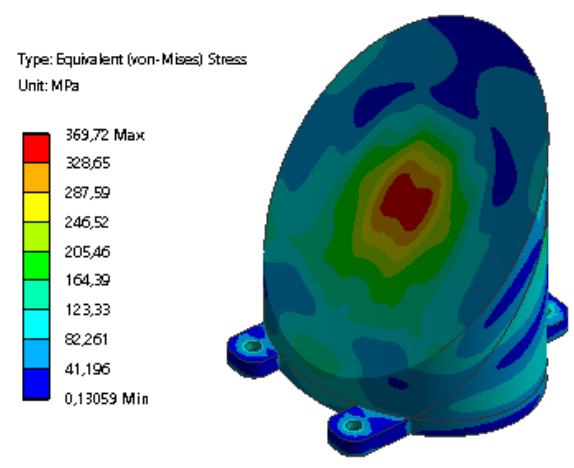

b)

Figure 9 - Thermal stresses on cooled stainless steel a) pre-launcher mirror M0 and b)

launcher mirror M1.

Since the stainless steel mirrors did not perform well in terms of thermal stresses, $\mathrm{CuCrZr}$ models were produced and the analyses repeated. The transient thermal analyses of the non-cooled models revealed peak temperature values of $202.6^{\circ} \mathrm{C}$ and $274.8^{\circ} \mathrm{C}$, respectively for mirrors M0 and M1. In both cases, the peak temperatures were below the operating limit of $350^{\circ} \mathrm{C}$ and steady-state conditions were reached before the analysis end time. Static structural analyses were then conducted, revealing maximum stress values on both mirror surfaces below 110MPa, as shown in Figure 10.

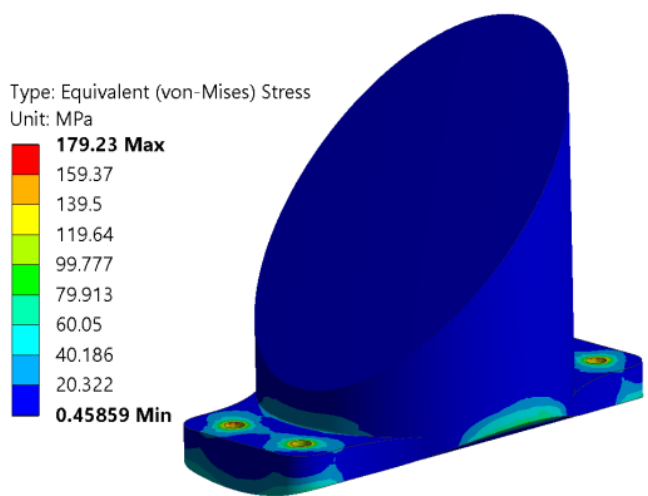

a)

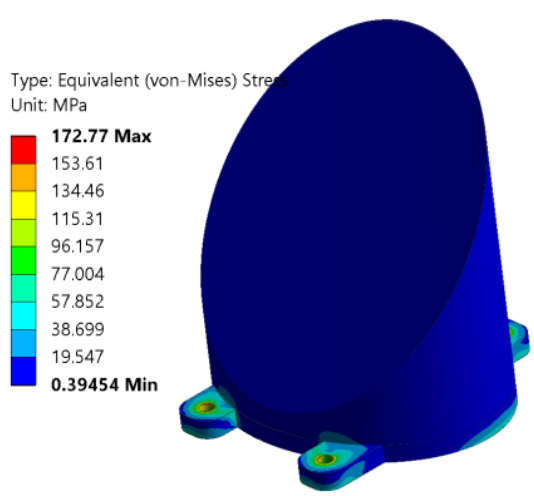

b)

Figure 10 - Thermal stresses on non-cooled $\mathrm{CuCrZr}$ a) pre-launcher mirror M0 and b) launcher mirror M1.

\subsection{Primary Receiver Mirror M2}

A transient thermal analysis with a pulse of 400 seconds was performed on a non-cooled stainless steel 316L (N)-IG primary receiver mirror M2 using the setup defined in sub-section 2.4.2. A peak temperature value of $478.4^{\circ} \mathrm{C}$ was obtained as shown in Figure 11 a), which is higher than the allowable limit of $450^{\circ} \mathrm{C}$. Furthermore, steady-state conditions were not reached before the analysis end time. 
In order to decrease the peak temperature on the mirror, a cooled model was developed and a similar transient thermal analysis performed. A peak temperature below the limit of $450^{\circ} \mathrm{C}$ was then computed, as presented in Figure $11 \mathrm{~b}$ ). The need to cool receiver mirrors was likewise found in the similar analysis of a CTS mirror placed on the high-field-side [8].

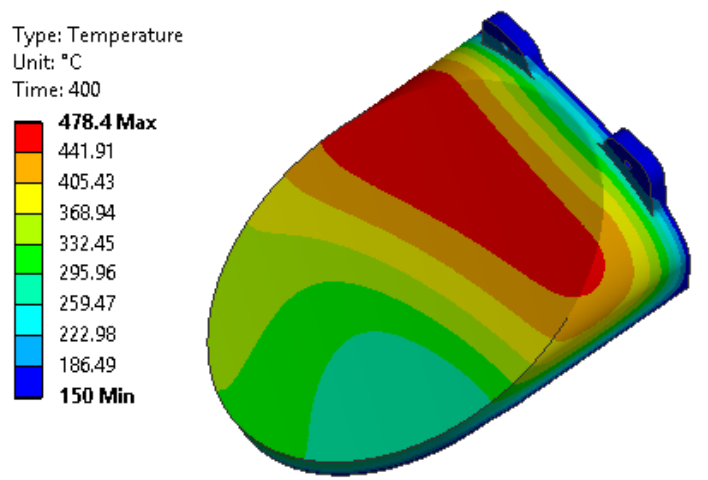

a)

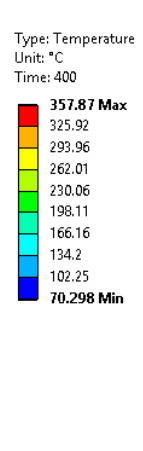

$57.87 \mathrm{Max}$

10225
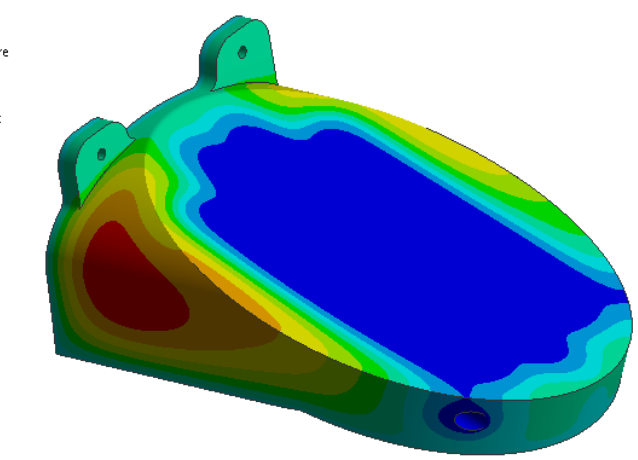

b)

Figure 11 - Temperature distribution on the stainless steel mirror M2 a) non-cooled model and b) cooled model.

The static structural analysis performed using as input this temperature distribution revealed high stress values across the mirror (Figure 12).

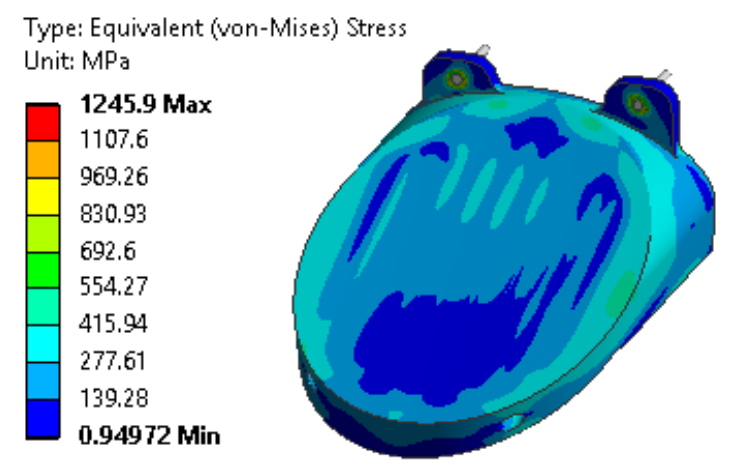

Figure 12 - Thermal stresses on the actively cooled stainless steel primary receiver mirror M2.

Based on the previous results, a new set of analyses was carried out considering the $\mathrm{CuCrZr}$ alloy. For a non-cooled model, the temperature distribution results of the transient thermal analysis showed that the peak temperature is well below the operating limit of $350^{\circ} \mathrm{C}$ (see Figure 13). 


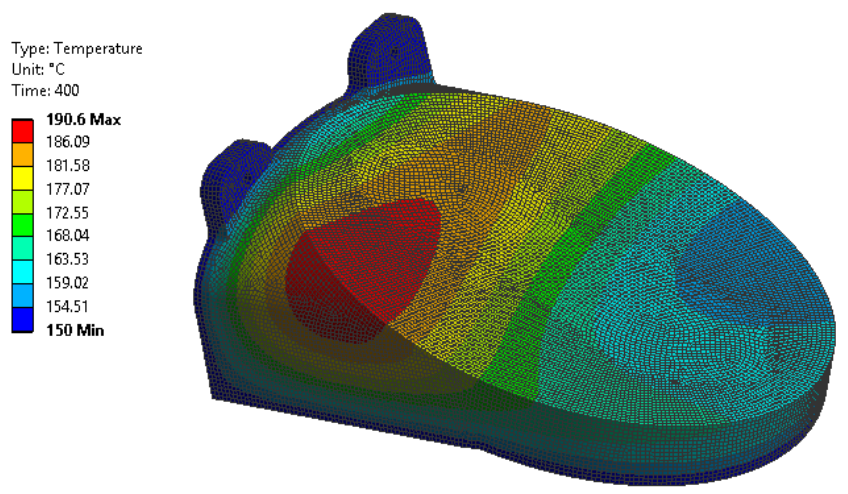

Figure 13 - Temperature distribution on the non-cooled $\mathrm{CuCrZr}$ primary receiver mirror M2.

A static structural analysis was then carried out, revealing stresses below 50MPa on the mirror surface.

\subsection{Launcher Mitre Bends}

As described in sub-sections 3.2 and 3.3, a transient thermal analysis of a non-cooled stainless steel mitre bend model was first performed. A maximum temperature of $713^{\circ} \mathrm{C}$ was obtained, higher than the maximum operating temperature of the material, i.e., $450^{\circ} \mathrm{C}$.

This model was then modified by increasing the thickness of the mirrors and afterwards, as the maximum temperature on the mirrors was still higher than $450^{\circ} \mathrm{C}$, by changing the material of the mirrors to the $\mathrm{CuCrZr}$ alloy. Regardless of these modifications the two mirrors and the two housings reached temperatures higher than $350^{\circ} \mathrm{C}$ (maximum operating temperature of $\mathrm{CuCrZr})$.

A cooled model was thus developed. The cooling arrangement presented in Figure 14 was implemented and the CuCrZr alloy was selected as the mitre bend mirrors and housings material. Afterwards, a new transient thermal analysis was carried out and the results are presented in Figure 15.

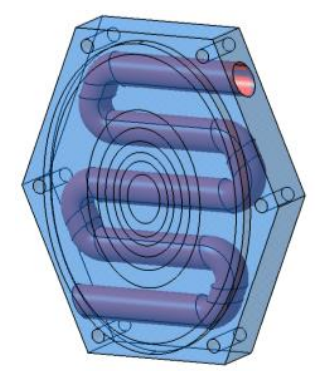

Figure 14 - Cooling arrangement in the mitre bend mirrors. Cooling channel diameter: $16 \mathrm{~mm}$. 


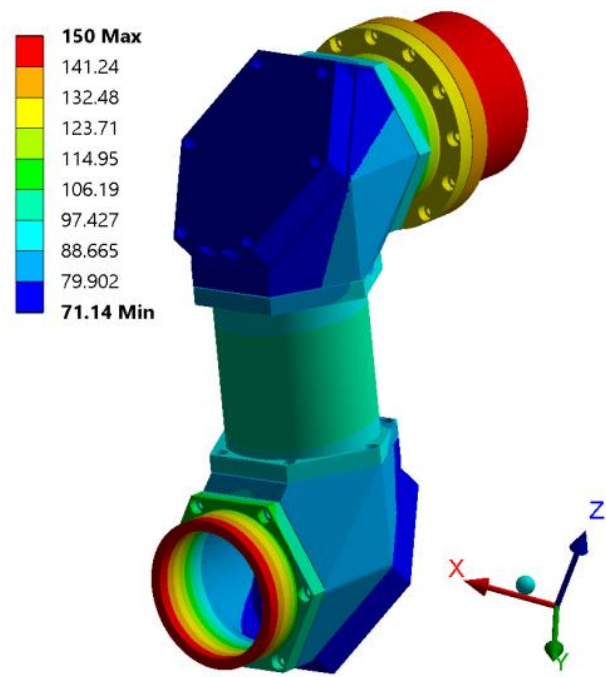

Figure 15 - Temperature distribution on a cooled mitre bend. Values in ${ }^{\circ} \mathrm{C}$.

In this model, the maximum temperature value was constrained by the imposed temperature on the enclosure $\left(150^{\circ} \mathrm{C}\right)$ and below the allowable temperature value $\left(350^{\circ} \mathrm{C}\right)$. A static structural analysis, using as input the thermal map showed in Figure 15, was then conducted.

Since the displacements are particularly important on the mirrors due to possible variations in the resulting beam propagation, these were isolated and are depicted in Figure 16.

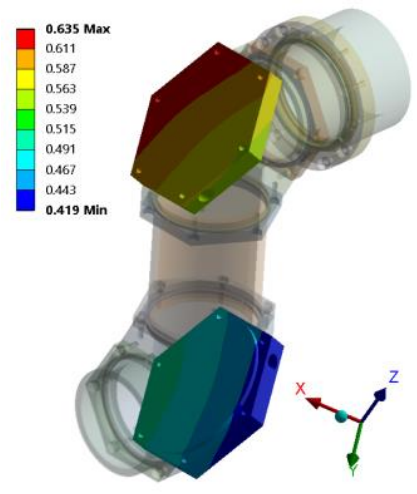

a)

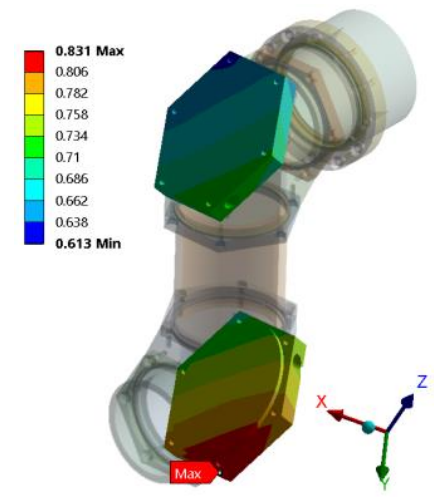

b)

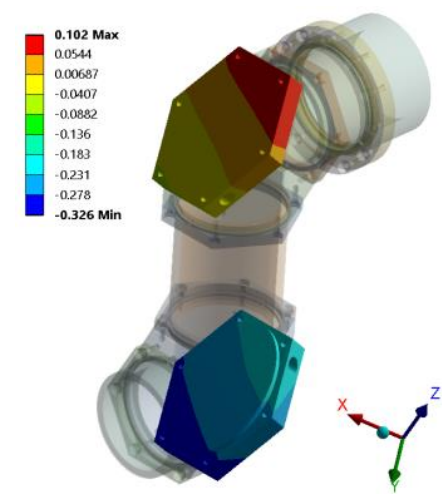

c)

Figure 16 - Displacement in the: a) $\mathrm{X}$ axis, b) $\mathrm{Y}$ axis and c) $\mathrm{Z}$ axis. Values in $\mathrm{mm}$.

The thermal stresses map revealed some critical points that will be further analysed according to the RCC-MR code [17] requirements. These points are mainly located on the housings.

\section{Conclusions}

The temperature distribution, thermal stresses and deformation results obtained for some in-vessel components of the CTS system are presented and discussed herein. The application 
of two different materials was also analysed for geometries with and without active cooling, with the objective of meeting the thermal and structural requirements.

Regarding the stainless-steel launcher mirrors, no feasible solutions were found since the geometries without active cooling do not comply with the operating temperature limit and the geometries with active cooling present high stresses. For the $\mathrm{CuCrZr}$ launcher mirrors, both cooled and non-cooled geometries comply with the temperature operating limit of $350^{\circ} \mathrm{C}$. Regarding the components' strength, the non-cooled geometries present higher safety factors but higher values for maximum total displacements. If the displacement values are proven to be within the tolerable limits, the non-cooled geometries should be the preferred solution since its manufacturing and application are simpler.

In the case of the primary receiver mirror, when using stainless steel with a non-cooled geometry, the operating temperature limit is not achieved. Besides, when active cooling was used, the obtained peak thermal stress was above the material yield strength. As for the $\mathrm{CuCrZr}$ primary receiver mirror, both cooled and non-cooled geometries comply with the temperature operating limit of $350^{\circ} \mathrm{C}$. The non-cooled geometry has a lower total displacement but a lower safety factor for stress. Nonetheless, this safety factor should be acceptable, and the non-cooled geometry should be the preferred solution.

Regarding the launcher mitre bends it was concluded that, even though they are not directly exposed to the plasma radiation, active cooling is still required. With active cooling it is easy to meet the maximum operating temperature, but not the yield stress requirement. One model with active cooling performed well (either considering thermal and structural requirements) for most components, except for one of the mitre bends housings. It was also concluded that using the $\mathrm{CuCrZr-IG}$ alloy, the temperatures reached, and the respective thermal stresses, are much lower than those obtained with stainless steel 316L (N)-IG.

The results overview is presented in Table 4. 


\begin{tabular}{|c|c|c|c|c|}
\hline Component & Material & $\begin{array}{l}\text { Active } \\
\text { cooling }\end{array}$ & $\begin{array}{l}\text { Peak temperature } \\
\left({ }^{\circ} \mathbf{C}\right)\end{array}$ & $\begin{array}{c}\text { von-Mises stress } \\
(\mathrm{MPa})\end{array}$ \\
\hline \multirow{3}{*}{$\begin{array}{l}\text { Pre-launcher } \\
\text { mirror, M0 }\end{array}$} & \multirow[t]{2}{*}{ SS 316L(N)-IG } & no & $609($ not ok; > 450) & not computed \\
\hline & & yes & $\begin{array}{l}269(\mathrm{ok} ;<450) \\
203(\mathrm{ok} \cdot<350)\end{array}$ & $\frac{520(\text { not ok; > 131) }}{<110(\mathrm{ok})}$ \\
\hline & CuCrZn-IG & $\begin{array}{c}\text { no } \\
-\end{array}$ & $\begin{array}{c}- \\
-\end{array}$ & $\begin{array}{c}-10(0 \mathrm{~N}) \\
-\end{array}$ \\
\hline \multirow{4}{*}{$\begin{array}{l}\text { Launcher } \\
\text { mirror, M1 }\end{array}$} & \multirow{2}{*}{ SS 316L(N)-IG } & no & 533 (not ok; > 450) & not computed \\
\hline & & yes & $207(\mathrm{ok} ;<450)$ & $370($ not ok; > 142) \\
\hline & \multirow{2}{*}{ CuCrZn-IG } & no & $275(\mathrm{ok} ;<350)$ & $<110(\mathrm{ok})$ \\
\hline & & yes & - & - \\
\hline \multirow{4}{*}{$\begin{array}{l}\text { Receiver } \\
\text { mirror, M2 }\end{array}$} & \multirow{2}{*}{ SS 316L(N)-IG } & no & $478($ not ok; > 450) & not computed \\
\hline & & yes & $358(\mathrm{ok} ;<450)$ & 1246 (not ok) \\
\hline & \multirow{2}{*}{ CuCrZn-IG } & no & $191(\mathrm{ok} ;<350)$ & $<50(\mathrm{ok})$ \\
\hline & & yes & - & - \\
\hline \multirow{4}{*}{$\begin{array}{l}\text { Launcher } \\
\text { mitre bend }\end{array}$} & \multirow{2}{*}{ SS 316L(N)-IG } & no & $713($ not ok; > 450) & not computed \\
\hline & & yes & - & - \\
\hline & \multirow{2}{*}{ CuCrZn-IG } & No & $>350$ (not ok) & not computed \\
\hline & & yes & $150(\mathrm{ok} ;<350)$ & $>381$ (not ok) \\
\hline
\end{tabular}

Table $4-$ Summary of results.

\section{Acknowledgements}

The work leading to this publication has been partially funded by Fusion for Energy (F4E) under the Specific Grant Agreement F4E-FPA-393-SG04. IST activities also received financial support from Fundação para a Ciência e Tecnologia (FCT) through project UID/FIS/50010/2013 and through the individual grant PD/BD/114322/2016 under the APPLAuSE Doctoral Program. This publication reflects the views only of the authors, and Fusion for Energy cannot be held responsible for any use, which may be made of the information contained herein.

\section{References}

[1] ITER Organization, "About: In a few lines," [Online]. Available: https://www.iter.org/proj/inafewlines. [Accessed 15 March 2018].

[2] M. Salewski et al 2018 Nucl. Fusion 58096019.

[3] S.B. Korsholm, et al., Collective Thomson scattering capabilities to diagnose fusion plasmas Nucl. Instr. Meth. Phys. Res. A, 623 (2010), pp. 677-680.

[4] S.B. Korsholm, et al., Measurements of intrinsic ion bernstein waves in a Tokamak by collective Thomson Scattering Phys. Rev. Lett., 106 (2011), p. 165004 
[5] M. Stejner, et al., The prospect for fuel ion ratio measurements in ITER by collective Thomson scattering Nucl. Fusion, 52 (2012), p. 023011

[6] M. Salewski, et al., Comparison of collective Thomson scattering signals due to fast ions in ITER scenarios with fusion and auxiliary heating Plasma Phys. Control. Fusion, 51 (2009), p. 035006

[7] S.B. Korsholm, et al., High power microwave diagnostic for the fusion energy experiment ITER IEEE 2016 1st International Conference on Infrared, Milimeter, and Terahertz Waves, Sep 25-30(2016)

[8] Salewski et al (2008) Rev. Sci. Instrum. 79 10E729

[9] A. Lopes et al., Neutronics analysis of the ITER Collective Thomson Scattering system, Fus. Eng. Des. 134 (2018) 22-28.

[10] S. Timoshenko, D. H. Young, and W. Weaver, Vibration Problems in Engineering (Wiley, New York, 1974).

[11] ITER, Appendix A, Materials Design Limit Data, ITER_D_222RLN, v3.3, Jan 2013.

[12] ITER Vacuum Vessel Load Specification, ITER_D_2F52JY, v.3.4, Feb. 2017.

[13] SG04 Deliverable D09 Low Field Side Collective Thomson Scattering - Load Specification, F4E_D_27UWCF, v3.0, Jun 2017.

[14] ITER Material Properties Handbook, ITER_D_24L79N, v1.1, Sep 2007.

[15] D05 CTS system Design Description Document (DDD) for the PADR, F4E_D_295TZX, v1.1, Jun 2017.

[16] ITER, 55.F3 - PPR: Load Specification for In-Vessel components, ITER_D_9QWLQ8, $\mathrm{v} 2.2,2015$.

[17] Design and Construction Rules for Mechanical Components of Nuclear Installations, AFCEN, Edition 2007. 